\title{
Internal Hemorrhoid
}

National Cancer Institute

\section{Source}

National Cancer Institute. Internal Hemorrhoid. NCI Thesaurus. Code C35319.

A hemorrhoid which originates above the dentate line. 